\title{
Between Exclusion and Inclusion: On the Challenges Facing World Heritage Preservation Efforts
}

\author{
Magdalena Marcinkowska: Liverpool delisted, Vienna \\ threatened to be on the List of the World Heritage in Danger, \\ similarly as Bialowieza Forest - those were the headlines of \\ many newspapers before the 41st session of World Heritage \\ Committee held in Poland. What were some of the outcomes \\ of the session?
}

Mechtild Rössler: Definitely, it was not an easy session! I observed that there is a growing uneasiness about the way the World Heritage Committee is taking some decisions in terms of nominations and the state of conservation. Certainly some decisions made at this year's session will stand the test of time, but others may not. Let me start with the state of conservation decisions: It was very interesting to follow the discussion on Bialowieza Forest. The final outcome was positive, considering that no opening for a discussion was foreseen in the first place. In essence, the originally proposed decision stood, as it was adequate. Another example, Vienna: During the debate

\footnotetext{
* Mechtild Rössler is the Director of the Division for Heritage and the UNESCO World Heritage Centre. She holds a Ph.D. from the Faculty for Earth Sciences, University of Hamburg (Germany). An expert in both cultural and natural heritage and the history of planning, Dr. Rössler has worked and taught in Europe and North America. She has published and co-authored 13 books and more than 100 articles.
} 


\section{INTERVIEWS}

Mechtild Rössler talks to Magdalena Marcinkowska

the Committee pointed out that the government and the local authorities were not implementing what was requested, and therefore included the city on the List of World Heritage in Danger. The Committee considered that such an alert was necessary. This Committee decision was fully supported by most in the room, including civil society. As for Liverpool, the Committee decided to give another warning to the British government. If the State Party does not fulfil its obligations and halts the granting of planning permissions, which has a negative impact on the Outstanding Universal Value of the Liverpool - Maritime Mercantile City, it might result in delisting next year. But I believe that there is some hope, as we have established a dialogue.

\section{MM: Were there any cases of removal from the List of World Heritage in Danger and return to the World Heritage List?}

In terms of removal, there were two interesting cases: First, Bagrati Cathedral and the Gelati Monastery in Georgia. According to the Decision, the Committee considered reducing the boundaries of the site, to exclude the Bagrati Cathedral as it has undergone major reconstruction detrimental to its value, integrity, and authenticity. This solution made it possible to retain the Gelati Monastery as a World Heritage site, and subsequently removed it from the List of World Heritage in Danger. The second case showed the commitment of the State Party. Due to continuous efforts of the Côte d'Ivoire government, it was possible to reduce poaching in Comoé National Park. As a result, populations of iconic species such as elephants and chimpanzees are now increasing and the state of conservation of the site has improved. The Committee's decision to remove it from the List of World Heritage in Danger was very satisfying and was much applauded in the room.

\section{MM: Any Committee decisions you did not support?}

It is not up to me to agree or disagree with Committee Decisions - as Secretariat we have to implement them. However, some decisions are not adequate. For example, the authorities of Pakistan decided to construct a metro line next to the Fort and Shalamar Gardens in Lahore. Last year, the Committee decided that there should be a reactive monitoring mission. Throughout the whole year we tried everything, but there was simply no answer from the State Party to this request by the Committee, and no mission could be carried out. At the session, the Committee members did not go along with the original proposal to include the site on the List of World Heritage in Danger to alert the international community to these threats. Many countries view the Danger Listing as negative, which is not as intended by the 
drafters of the Convention, who envisaged it as a tool to gain assistance and support. This was also the case for Nepal and the Kathmandu Valley. There are very clear provisions in the Operational Guidelines that sites which are under threat, whether from human causes or natural disasters, should be placed on the List of World Heritage in Danger to gain more attention and support from the international community, including financial support. Inscription on the List of World Heritage in Danger implies activities directed towards addressing all the issues identified, followed by projects on the ground. Unfortunately, the Committee does not fully use the provisions of the List of World Heritage in Danger, and I think more support needs to be given to the site authorities and governments to cope with disaster situations and destruction.

I am not content with decisions which are inconsistent with the provisions of the Operational Guidelines. However, the situation for nominations may be even more critical. I strongly believe that only sites of Outstanding Universal Value should enter the World Heritage List and the Committee should make best use of the decisive moment when a Government wishes to propose a nomination to get it right, including the Statement of Outstanding Universal Value, integrity, authenticity, and management.

\section{MM: Does it mean that the List should be closed one day?}

No, of course not. While collecting information for the book I wrote with Professor Christina Cameron, former Chairperson of the Committee, Many Voices, One Vision: The Early Years of the World Heritage Convention, we conducted interviews with the "founding fathers and mothers" of the 1972 UNESCO Convention. There is of course a diversity of views, but in essence the List cannot be closed, and we should not forget that the List is only for sites of Outstanding Universal Value. However, in recent years we are getting more and more proposals concerning sites of questionable value, more of regional or local importance rather than international. Let's start with the natural sites: The crux of the matter is that there we have a better assessment system for a comparison - for instance the number of endemic species in one site - which can be compared to another. These assessments are also based on global databases on protected areas, and they are scientific. For cultural sites, it is much more complicated because each of those sites has to be assessed within a given culture. Furthermore, there is no other listing system for cultural sites under international law. We have a listing system for intangible heritage elements under the 2003 Convention for the Intangible Cultural Heritage, but it does not apply to sites. The problem the World Heritage Committee is faced with is that many 


\section{INTERVIEWS}

Mechtild Rössler talks to Magdalena Marcinkowska

countries wish to have recognition of their heritage sites, and they apply for World Heritage listing also for short-term economic and tourism gains. For natural sites it is different, as there are other instruments. A country can apply for a Ramsar site under the 1971 Ramsar Convention on Wetlands, for a UNESCO Biosphere Reserves or Geopark, and in Europe for Natura 2000 etc. These other options do not exist for cultural sites. The other side of the problem is the increasing political pressure.

\section{MM: Does all this mean that the World Heritage protection system is in crisis? The amount of money available for each site in the last few years has been de- creasing and political interests are about to overshadow the meaning and goals of protection...}

It is not true that there is no money in the World Heritage system. There is a lot of money, but the problem is that the money is in the wrong place. Sometimes the local authorities or the Government are spending US $\$ 5-10$ million or even more for the nomination of a World Heritage site. Therefore, it is not true that there is no money. But the money is not there to safeguard the sites in countries of need and for heritage conservation in general. I see this as a serious challenge, so far without any long-term solution. It is also true that there is much more political pressure to get sites inscribed, and I think national authorities feel this as well. Furthermore, there are fewer experts in the Committee who know the Operational Guidelines, processes, and procedures, and who are able to speak up and say a site is not ready to be inscribed. Let's take for instance Wadi Rum in Jordan, a mixed site - inscribed for both its natural and cultural values. I headed a reactive monitoring mission with IUCN and ICOMOS to this incredible place four years after the inscription. Originally, the Advisory Bodies' evaluation of the nomination recommended deferral for the cultural part and referral for natural. The Committee however inscribed the site immediately and included all the recommendations from the Advisory Bodies at the end of the decision, asking the State Party to implement them. After four years, not one request from the Committee was completed, but we used the mission to explain what needed to be done and we established a good cooperation.

\section{MM: How about the political pressure?}

I am not saying that the Committee needs to follow all the recommendations of the Advisory Bodies - of course not, as it is an independent body. The crux of the matter is that you rarely hear an expert opinion; instead you hear a statement from the representatives of one country given in favour of another State to in- 
scribe a site. I have been following this Convention since 1991, and I have to admit that, for me, this recent situation is quite amazing. Honestly, there are no easy solutions. In the past, the Committee would add a criterion to a site during the inscription process. Today you do not hear anything like that. Nowadays, the Committee is not able to adopt any Statement of Outstanding Universal Value for sites proposed for referral or deferral for which the Advisory Bodies have not proposed one. So, they decide that in such a case they will go straight for inscription, attaching only a provisional statement. In some cases we face even more serious issues. For instance, in 2017 the Committee adopted a decision asking to send a map of the property inscribed, including the buffer zone, by 1 December. If a disaster would happen the next day, the World Heritage Centre would not precisely know where the site is located. The other problem is that many representatives are not fully familiar with the Operational Guidelines and the Rules of Procedures of the World Heritage Committee. I always underline that the 1972 UNESCO World Heritage Convention is about expertise concerning whether a site is clearly of Outstanding Universal Value. This is mentioned in the Convention, which requests that "States members of the Committee shall choose as their representatives persons qualified in the field of the cultural or natural heritage" (Article 9.3).

\section{MM: Was it always like that?}

Before the year 2000 there was a kind of screening process, and there were recommendations made by the Bureau, for example for nominations which had no management plan, no clear map, or for which no comparative studies had arrived at the Committee meeting. But then it was decided that the Bureau is too powerful and it is a prerogative of the Committee to make such decisions. No one assumed that this might politicize the Committee. Under the current serious financial constraints, I do not think that we need so many new inscriptions on the List every year, although maybe with some exceptions for underrepresented categories of heritage or regions not yet well represented, such as sub-Saharan Africa, the Pacific, or the Caribbean. For example, this year we had Angola and Eritrea obtaining their first inscriptions on the World Heritage List, and it was a very happy moment for all of us.

MM: During the session there were many side events, one of which considered the bridges between the 1972 and 2003 Conventions. Do you believe that the legal orders between tangible and intangible heritage should be complementing one another? 


\section{INTERVIEWS}

Mechtild Rössler talks to Magdalena Marcinkowska

First of all, I want to stress that these two Conventions have different objectives: one concerns sites of Outstanding Universal Value, the other concerns intangible heritage elements. On the other hand, many World Heritage sites are linked to intangible cultural heritage elements. Take for instance the Kaya Forests in Kenia, a World Heritage site. It was the traditional knowledge of the elders which actually protected this heritage long before the place was gazetted. It was fantastic that they safeguarded the sacred places and these knowledge systems are recognized as an element on the Representative List of the Intangible Cultural Heritage. These two Conventions are therefore complementary, but they should not be mixed up. Synergies between those two Conventions can be made especially through capacity-building. Last year, there was a meeting of experts considering cultural heritage under threat, discussing how to deal with the damaged heritage in Syria. Under the 1972 UNESCO Convention we have the List of World Heritage in Danger, providing assistance to the archaeological sites such as Palmyra or the city of Aleppo. At the same time, we need to remember that the intangible cultural heritage of Syria is also very much under threat, maybe even more so than the tangible. Take the case of music - in cases like this, working hand in hand in places such as with the destruction in Aleppo means that the places where the music was performed also no longer exist. Rehabilitation of the city will make people return one day, and the intangible culture will once again be present.

\section{MM: Do you think there is a chance for the sites from Syria inscribed at the WHL in Danger to come back on the World Heritage List? What is UNESCO's plan for them, since reconstruction is forbidden?}

That is a very important issue. There are provisions in the Operational Guidelines that reconstruction is allowed only in exceptional circumstances, and that was integrated after the inscription of the Old Town in Warsaw, Poland. In another case - the Mostar Bridge in Bosnia and Herzegovina - the Committee refused to use criterion (iv) for the architecture, and only inscribed the site of its associative values under criterion (vi). At the Committee, we spent hours in debate, which was very difficult for the team from Bosnia and Herzegovina. The current discussion about reconstruction started much earlier with the case of the destruction of the statues of Bamiyan Buddhas in 2001, and it concerns especially cases of intentional destruction. In my personal opinion not everything needs to be reconstructed; look at the Gedächtniskirche in Berlin. I went to Palmyra in 2016 to do the rapid assessment with a team there. The temple of Baalshamin is totally destroyed. So the question is: Do we need to reconstruct it? Today we have many methods to keep 
the memories of the original site, for instance 3D models. The debate concerning the necessity of reconstruction is much needed and requires intricate knowledge of each situation. For the Triumphal Arch, to give another example from Palmyra, it is much easier. The stones just collapsed, so the Department of Antiquities considers that they could be put up again. We should also think carefully what the priority is at the moment. The Action Plans for heritage Syria need to be carefully looked at. Assistance for Aleppo may be the most urgent, because people will be moving back to the city. If we do not act now, some of the remaining cultural elements, architectural monuments, and building structures may simply be gone. The most serious situations among all Syrian sites inscribed on the List of World Heritage in Danger are undoubtedly in Aleppo and Palmyra. What I really wish to see is that the international community unites and assists to stop illicit trafficking coming out of these sites and the region, and helps us to recover the heritage and work with the communities in rebuilding their identity and heritage.

\section{MM: What is the relation between terms reconstruction, rehabilitation, and re- covery?}

At UNESCO, we like the word "recovery". This is the more encompassing term, which means that the local community needs to be involved and integrate their visions of how they see their recovery. The case of Timbuktu is a good example. The rehabilitation and reconstruction of the Mausoleums destroyed in 2012 succeeded because of the involvement of the local communities. People were rebuilding their mausoleums while respecting the local traditions and building methods of earthen architecture known for generations. This is a great example of how the transmission of knowledge, wisdom, and tradition, also including intangible cultural heritage, are safeguarding World Heritage sites at the same time.

\section{MM: Another issue considered world heritage sites and sites of memory. Does UNESCO have any specific policy considering their protection?}

Sites inscribed only under criterion (vi) are protected at the same level as other sites. What is worth pointing out is that only a few sites have been inscribed under this criterion for their associative values in the history of the Convention. Further studies on this topic are much needed and will be more focused, for two reasons. First, there is a growing number of sites being nominated for the World Heritage List also for their associative values. There are many State Parties interested in this matter, like Rwanda for instance, which is preparing the notion of a genocide site, or some of the European countries, which are considering applying for the recognition 


\section{INTERVIEWS}

Mechtild Rössler talks to Magdalena Marcinkowska

of war sites and graveyards and other places of memory. I need to point out that the List is not for every site; the List is only for sites of clear Outstanding Universal Value. Sites inscribed need to have physical evidence to which the memory is related, for example Auschwitz Birkenau - the German Nazi Concentration and Extermination Camp (1940-1945). In 2012 an expert meeting concerning the meaning of criterion (vi) was held in Warsaw, Poland. Reflections on this topic started then and are now continuing. One of the provisions in the Operational Guidelines is that it is only possible to inscribe a site under criterion (vi) in exceptional circumstances, or using other criteria as well. Secondly, there are a number of sites inscribed under other criteria, and they also may in some cases be important for the memory of people. Those two issues are currently analysed and will be further discussed at the next Committee session in 2018.

\section{MM: What is the most problematic issue of the 1972 Convention that needs to be resolved in the near future?}

The increase in nominations of sites which do not have clear Outstanding Universal Value, and that are nominated only to fulfil short-term economic needs or sometimes for political purposes. It is clear that political pressures exist. Most importantly, funding should not focus on nominations, but should be given to sites for their conservation. This Convention is about intergenerational equity! We are here to save the most unique and outstanding places on earth for the generations to come, and if we do not do this, then this Convention and its implementation will be no longer credible in the eyes of people around the world. 